\title{
Toward Quality of Cardiovascular Preventive Care for Patients with Rheumatic Diseases
}

Cardiovascular disease (CVD) in various guises represents perhaps the most important comorbidity in patients with rheumatic diseases. This is best studied in patients with rheumatoid arthritis (RA), who have consistently been reported to have significantly elevated CVD risk as compared to their peers in the general population ${ }^{1,2}$. Over the past decade, the roles of RA-associated and conventional risk factors in the pathogenesis of CVD have been delineated ${ }^{3}$. The importance of treating the joint disease to target has been established, focusing on abating systemic inflammation, which may conceivably minimize the risk of $\mathrm{CVD}^{4,5}$. Emerging evidence suggests that we may be contributing to improved survival of patients with RA, but evidence remains of a persisting mortality gap between patients with RA and the general population ${ }^{5,6,7,8}$.

Considering this information, it should be considered a priority to establish standards of preventive care that are specific to patients with RA (and eventually, other rheumatic diseases). Indeed, there is evidence pointing to variation in practice and to deficiencies in recognition and treatment of traditional $\mathrm{CV}$ risk factors in patients with $\mathrm{RA}^{8,9}$. The ultimate goal of developing RA-specific guidelines for CVD primary prevention would be to facilitate broader understanding of best practices and provide metrics for rheumatology care providers to ensure they are delivering high-value care toward primary prevention of CVD in patients with RA.

In this issue of The Journal, Barber and colleagues report recommendations for 11 quality indicators (QI) for CVD preventive care for implementation in practice settings ${ }^{10}$. The concept of QI as reviewed by the authors is important because it incorporates statements about the best specific processes or outcomes of care that can be further developed into performance measures. The investigators first conducted a thorough systematic review of best practices for CVD preventive care, the results of which are published ${ }^{11}$. They formed an in-person expert panel involving 6 experts to develop candidate QI, then convened online an international, multidisciplinary, modified-Delphi panel using the RAND/UCLA appropriateness methodology 12 . An innovative aspect of this work is the application of a RAND-developed software platform, ExpertLens, to conduct online review and discussion of the QI, which importantly enabled the consideration of input from experts across the globe in a cost- and time-efficient manner. Participation by the online expert panel was very good. The methodology used is considered the best available to establish evidence-and consensus-based QI. The final criteria for acceptance of the QI by the expert panel - including relevance to quality of care in RA practice, feasibility in actual practice settings, validity as a measure of the quality of CVD preventive care, and recommendation for use in rheumatology practice - were appropriate. There is evidence that the final set of QI had good ratings by the expert panel in these attributes, underscoring their overall significance to primary CVD prevention in the RA population.

The developed QI comprise statements about key processes to achieve primary CVD prevention in the RA population along with specification of what is to be measured, in whom, and in what period of time ${ }^{10}$. Addressed by these QI are (1) communication of increased CVD risk to primary care providers, (2) performance of CVD risk assessment, (3) smoking assessment and cessation counseling, (4) blood pressure monitoring, (5) communication to the primary care provider regarding blood pressure elevation, (6) lipid screening, (7) diabetes screening, (8) exercise, (9) obesity screening and lifestyle counseling, (10) minimizing corticosteroid usage, and (11) communicating risk of treatment with nonsteroidal antiinflammatory drugs in patients at elevated CVD risk. Management of inflammatory disease activity itself was not addressed because that is detailed in other guidelines. In the appendix, the authors nicely detail the QI, including key information on the numerator, denominator, exclusions, and period of assessment for each of these measures.

Importantly, the authors have chosen to focus on process as opposed to outcome measures, which is appropriate, considering the relative infrequency of CVD events in rheumatologic practice ${ }^{13}$. A strength of this work is the philosophy to attach a specific screening procedure (e.g., detection of a patient with blood pressure above 140/90 $\mathrm{mmHg}$ ) with a specific clinical action (e.g., advising the

See CV quality indicators for RA, page 1548

Personal non-commercial use only. The Journal of Rheumatology Copyright (C) 2015 . All rights reserved. 
primary care provider of the need for treatment or additional followup). In so doing, these guidelines encourage adoption of processes that should enhance CVD prevention, and quite simply, that should be viewed as good clinical practice.

Nonetheless, as with all clinical guidelines and QI, there are a number of limitations of this work. The main issue is feasibility. Rheumatologists in the community face critical time deficiencies, typically with only 15 minutes total per patient (much of which must be dedicated to navigating their electronic health record), leaving little time to address all of these issues. In this regard, it is very important to note that only $10 \%$ of the expert panelists represent community-based rheumatologists. The authors encountered difficulties enlisting such individuals to participate in this activity. The authors have appropriately acknowledged that the feasibility ratings might have differed substantially had more community providers been included in the expert panel. Additionally, some of the individual QI had marginally lower feasibility ratings, such as for CVD risk assessment based on risk score calculation (67.9\%). Some of the data required to implement some of the QI may not routinely be available in all practice settings (e.g., history of a macrosomic infant or metabolic syndrome). Ultimately, timely issues of practice redesign in the setting of time burden, challenges with electronic health records, and escalating costs of care must be addressed to improve CVD preventive care for patients with RA.

Another challenge is uncertainty and complexity in implementing recommendations for primary CVD prevention in rheumatology patients. First, guidelines for preventive screenings are becoming increasingly complex and sometimes controversial (e.g., the recent debate about 2013 American College of Cardiology/American Heart Association guidelines for treatment of blood cholesterol) ${ }^{14}$. Second, the available CVD risk assessment scores perform relatively poorly in predicting events in patients with RA; using an RA-specific risk modifier (1.5 multiplier) does not adequately mitigate this problem ${ }^{15,16}$. Third, inflammatory activity is known to confound certain assessments, particularly lipid levels, so rheumatologists may be uncertain as to when to implement these screening measures ${ }^{17}$. The time intervals for screening in the final set of QI represent expert consensus as opposed to evidence. Clarity on the implementation of these preventive guidelines must await improved understanding of the interactions between CVD risk factors and rheumatic disease.

Barber and colleagues are careful to state that the responsibility to meet these QI does not fall on the rheumatologist alone, but adequate resources and time are needed to coordinate this additional care on top of the typically complex care required for these patients. For quality indicators to be broadly adopted, healthcare systems must identify the most efficient and effective means of providing this care to their local RA populations. New collaborative care models may help facilitate implementation of CVD screening and management guidelines, such as the concept of "cardiorheumatology clinics," in which a preventive cardiologist works alongside rheumatologists to optimally assess CVD risk and recommend preventive interventions ${ }^{18,19}$. Efficient communication by team providers, ideally electronically, will be necessary to achieve truly collaborative care. Such new shared-care models of preventive care afford hope that best practices and QI can be implemented successfully.

Ultimately, the outstanding work by Barber and colleagues in establishing QI represents a crucial first step toward primary CVD prevention for populations of patients with RA. As discussed by the authors, further pilot testing and validation of the utility of these QI are needed. A great deal of effort will be necessary to provide the education and training necessary for rheumatologists, cardiologists, and primary care physicians to realize efficient, reliable, and high-quality CVD preventive care to persons with RA.

JOHN M. DAVIS, III, MD, MS,

Consultant, Division of Rheumatology; Associate Professor of Medicine, College of Medicine, Mayo Clinic, Rochester, Minnesota, USA.

Address correspondence to Dr. Davis, Mayo Building 15-73E, 200 1st St. SW, Rochester, Minnesota 55905, USA. E-mail: davis.john4@mayo.edu Supported by the US National Institutes of Health/US National Institute of Arthritis and Musculoskeletal and Skin Diseases HH R01 AR 46849. Dr. Davis received Pfizer research grant funding and was a site investigator for Genentech/Roche.

\section{REFERENCES}

1. Mackey RH, Kuller LH, Deane KD, Walitt BT, Chang YF, Holers VM, et al. Rheumatoid arthritis, anti-CCP positivity, and cardiovascular disease risk in the Women's Health Initiative. Arthritis Rheumatol 2015; May 18 (E-pub ahead of print).

2. Avina-Zubieta JA, Thomas J, Sadatsafavi M, Lehman AJ, Lacaille D. Risk of incident cardiovascular events in patients with rheumatoid arthritis: a meta-analysis of observational studies. Ann Rheum Dis 2012;71:1524-9.

3. Crowson CS, Liao KP, Davis JM 3rd, Solomon DH, Matteson EL, Knutson KL, et al. Rheumatoid arthritis and cardiovascular disease. Am Heart J 2013;166:622-8.e1.

4. Listing J, Kekow J, Manger B, Burmester GR, Pattloch D, Zink A, et al. Mortality in rheumatoid arthritis: the impact of disease activity, treatment with glucocorticoids, TNFalpha inhibitors and rituximab. Ann Rheum Dis 2015;74:415-21.

5. Radovits BJ, Fransen J, Al Shamma S, Eijsbouts AM, van Riel PL, Laan RF. Excess mortality emerges after 10 years in an inception cohort of early rheumatoid arthritis. Arthritis Care Res 2010; 62:362-70

6. Widdifield J, Bernatsky S, Paterson JM, Tomlinson G, Tu K, Kuriya $\mathrm{B}$, et al. Trends in excess mortality among patients with rheumatoid arthritis in Ontario, Canada. Arthritis Care Res 2015; Jan 26 (E-pub ahead of print).

7. Gonzalez A, Maradit Kremers H, Crowson CS, Nicola PJ, Davis JM 3rd, Therneau TM, et al. The widening mortality gap between rheumatoid arthritis patients and the general population. Arthritis Rheum 2007;56:3583-7.

8. Humphreys JH, Warner A, Chipping J, Marshall T, Lunt M, Symmons DP, et al. Mortality trends in patients with early

Personal non-commercial use only. The Journal of Rheumatology Copyright $\odot$ (2015. All rights reserved 
rheumatoid arthritis over 20 years: results from the Norfolk Arthritis Register. Arthritis Care Res 2014;66:1296-301.

9. Gossec L, Salejan F, Nataf H, Nguyen M, Gaud-Listrat V, Hudry C, et al. Challenges of cardiovascular risk assessment in the routine rheumatology outpatient setting: an observational study of 110 rheumatoid arthritis patients. Arthritis Care Res 2013;65:712-7.

10. Barber CE, Marshall DA, Alvarez N, Mancini JG, Lacaille D, Keeling S, et al. Development of cardiovascular quality indicators for rheumatoid arthritis: results from an international expert panel using a novel online process. J Rheumatol 2015;42:1548-55.

11. Barber CE, Smith A, Esdaile JM, Barnabe C, Martin LO, Faris P, et al. Best practices for cardiovascular disease prevention in rheumatoid arthritis: a systematic review of guideline recommendations and quality indicators. Arthritis Care Res 2015;67:169-79.

12. Fitch K, Bernstein SJ, Aguilar MD, Burnand B, LaCalle JR, Lazaro $\mathrm{P}$, et al. The RAND/UCLA appropriateness method user's manual. Santa Monica, CA: RAND Corporation; 2001. [Internet. Accessed June 25, 2015.] Available from: www.rand.org/pubs/monograph_reports/MR1269

13. Bombardier C, Hazlewood GS, Akhavan P, Schieir O, Dooley A, Haraoui B, et al. Canadian Rheumatology Association recommendations for the pharmacological management of rheumatoid arthritis with traditional and biologic disease-modifying antirheumatic drugs: part II safety. J Rheumatol 2012;39:1583-602.

14. Lopez-Jimenez F, Simha V, Thomas RJ, Allison TG, Basu A, Fernandes R, et al. A summary and critical assessment of the 2013
ACC/AHA guideline on the treatment of blood cholesterol to reduce atherosclerotic cardiovascular disease risk in adults: filling the gaps. Mayo Clin Proc 2014;89:1257-78.

15. Crowson CS, Matteson EL, Roger VL, Therneau TM, Gabriel SE. Usefulness of risk scores to estimate the risk of cardiovascular disease in patients with rheumatoid arthritis. Am J Cardiol 2012;110:420-4.

16. Arts EE, Popa C, Den Broeder AA, Semb AG, Toms T, Kitas GD, et al. Performance of four current risk algorithms in predicting cardiovascular events in patients with early rheumatoid arthritis. Ann Rheum Dis 2015;74:668-74.

17. Myasoedova E, Crowson CS, Kremers HM, Fitz-Gibbon PD, Therneau TM, Gabriel SE. Total cholesterol and LDL levels decrease before rheumatoid arthritis. Ann Rheum Dis 2010;69:1310-4.

18. Semb AG, Rollefstad S, van Riel P, Kitas GD, Matteson EL, Gabriel SE. Cardiovascular disease assessment in rheumatoid arthritis: a guide to translating knowledge of cardiovascular risk into clinical practice. Ann Rheum Dis 2014;73:1284-8.

19. Rollefstad S, Kvien TK, Holme I, Eirheim AS, Pedersen TR, Semb AG. Treatment to lipid targets in patients with inflammatory joint diseases in a preventive cardio-rheuma clinic. Ann Rheum Dis 2013;72:1968-74.

J Rheumatol 2015;42:1539-41; doi:10.3899/jrheum.150697 